\title{
RELIGIÃO E GÊNERO: UMA INVESTIGAÇÃO DO ESTADO DA ARTE DOS ESTUDOS DE GÊNERO NOS PROGRAMAS DE PÓS-GRADUAÇÃO EM CIÊNCIAS DA RELIGIÃO NO BRASIL
}

\author{
Clóvis Ecco* \\ Thaís Alves Marinho** \\ Claudete Ribeiro de Araújo***
}

\begin{abstract}
RESUMO
Por ocasião do festejo dos quarenta anos de existência das Ciências da Religião no Brasil, apresentamos este estudo, que busca examinar a distribuição de gênero masculino/feminino nos programas de Pós-Graduação em Ciências da Religião. Respondendo às seguintes questões: Como tem se configurado a distribuição de posições (entre docentes e discentes), em relação ao gênero masculino/feminino nos Programas de Pós-Graduação? O que os Programas de Pós-Graduação em Ciências da Religião têm produzido acerca da relação entre religião e gênero? Onde se encontram essas produções? O que essas pesquisas têm como lacunas e ausências? Quais contribuições e desafios as pesquisas trazem para a academia e para a sociedade, em geral? O recorte feito inclui as dissertações e teses defendidas entre 2000 a 2017 e a distribuição de cargos supracitados nos Programas de Pós-Graduação em Ciências da Religião. Mostraremos que o debate do campo de estudos sobre mulheres, feminino, homens,
\end{abstract}

* Doutor em Ciências da Religião pela Pontifícia Universidade Católica de Goiás (PUC-GO). Coordenador do Programa de Pós-Graduação Strictu Sensu em Ciências Sociais e da Religião da Pontifícia Universidade Católica de Goiás (PUC-GO). Professor titular de Pós-Graduação Strictu Sensu da Pontifícia Universidade Católica de Goiás (PUC-GO).

** Doutora em Sociologia pela Universidade de Brasília (UnB) e Pós-Doutora em Ciências Sociais pela Universidade do Vale dos Sinos (Unisinos). Coordenadora do Programa de Pós-Graduação em História da Pontifícia Universidade Católica de Goiás (PUC-GO).

*** Doutoranda em Ciências da Religião pela Pontifícia Universidade Católica de Goiás (PUC-GO). Mestra em História Social pela Pontifícia Universidade Católica de São Paulo (PUC-SP). Licenciada em Filosofia pela Faculdade Associada do Ipiranga e Bacharela em Teologia pela Faculdade de Teologia Nossa Senhora da Assunção. 
masculino gênero, corpo, sexualidades - relacionados à religião e às religiosidades possibilitam compreender quais respostas são dadas e como polemizam a categoria, bem como, se surgiram daí novas perspectivas de olhares teóricos.

Palavras-chave: Ciências da religião. Gênero. Mulheres. Sexualidades.

\title{
RELIGION AND GENDER: AN INVESTIGATION OF GENDER STUDIES' STATE OF ART IN THE RELIGION SCIENCES POST-GRADUATE PRO- GRAMS IN BRAZIL
}

\begin{abstract}
On the occasion of the forty years' celebration of the Sciences of Religion existence in Brazil, we present this study to examine the distribution of male/female gender in the Graduate Programs in Religion Sciences. Responding to the following questions: How has the distribution of positions (among teachers and students) been configured in relation to the male/female gender in the Graduate Programs? What have the Graduate Programs in Religion Sciences produced about the relationship between religion and gender? Where are these productions? What are the gaps and absences of these studies? What contributions and research challenges do they bring to the academy and to society in general? For that means, we analyze the dissertations and theses defended between 2000 to 2017 and the distribution of positions mentioned above in the Post-Graduate Programs in Religion Sciences. We will show that the debate of the field of studies on women/men, masculine/female gender, body, sexualities, and these related to religion and religiosities, makes possible to understand what answers are given and how they polemize the category, as well as whether new perspectives of theoretical views have emerged.
\end{abstract}

Key-words: Religion sciences. Genre. Women. Sexualities.

\section{RELIGIÓN Y GÉNERO: UNA INVESTIGACIÓN DEL ESTADO DE ARTE DE ESTUDIOS DE GÉNERO EN LOS PROGRAMAS DE POSTGRADUA- CIÓN DE CIENCIAS DE LA RELIGIÓN EN BRASIL}

\author{
RESUMEN \\ Con ocasión del festejo de los cuarenta años de existencia de las Cien- \\ cias de la Religión en Brasil, se presenta este estudio cuya propuesta \\ es mapear y examinar la producción discente de los programas de
}


Postgrado en Ciencias de la Religión, sobre el uso de la categoría de género en las temáticas que analizan las religiones, respondiendo a las siguientes cuestiones: ¿Qué han dado los Programas de Postgrado en Ciencias de la Religión acerca de la relación entre religión y género? ¿Dónde se encuentran esas producciones? ¿Lo que estas investigaciones tienen como huecos y ausencias? ¿Cuáles contribuciones y desafíos a las investigaciones traen para la academia y para la sociedad en general? El recorte hecho incluye las disertaciones y tesis defendidas entre 2000 a 2017. Transita por el debate del campo de estudios sobre mujeres, hombres, masculino, género, cuerpo, sexualidades, y estos relacionados a religión y religiosidades; señala como sus respectivos autores / as que abordan las matrices teóricas de estos estudios, cuáles respuestas dadas y cómo polemizan el uso de la categoría con las temáticas, así como, si surgieron de ahí nuevas perspectivas de miradas teóricas.

Palabras clave: Ciencias de la religión. Género. Mujeres. Sexualidades.

\section{INTRODUÇÃO}

O objetivo deste estudo é entender como as pesquisas na área de Ciências da Religião têm se debruçado sobre a categoria de gênero e quais as escolhas feitas pelos e pelas docentes e discentes que possibilitam a socialização com a comunidade acadêmica e com a sociedade diante das demandas sociais que envolvem desigualdades sociais de gênero.

Admitem-se aqui as diversas e múltiplas identidades de gênero, assumindo que o sistema binário é incapaz de compreender o gênero de todos os seres humanos, especialmente por meio de todas as culturas, e que essas categorizações são extremamente dinâmicas. Muitas sociedades estão agora expandindo a maneira como utilizam os termos de gênero, a partir da realidade empírica dos indivíduos que vivem em coletividades, o que corrobora as teorias, estudos e movimentos sociais de gênero e queers. Recentemente, por exemplo, New York passou a admitir e obrigar o reconhecimento de 31 tipos de gênero. O Facebook passou a disponibilizar 56 opções de gênero, na inscrição do perfil dos usuários. No entanto, pela dificuldade em identificar essa pluralidade nos bancos de dados empregados para a pesquisa, que nos permitem identificar o gênero apenas pelo nome social, ou pela indicação dos 
sexos masculino e feminino, metodologicamente optamos por delinear o recorte focando as categorias masculino e feminino.

Nossa hipótese é que as ciências da religião, assim como as demais, são uma construção social, desde o lugar epistemológico que as demarca, até as teorias que as assentam, até as técnicas e métodos de coleta, seleção e interpretação dos dados. Logo, são influenciadas pelo sistema de valores e pelas relações de poder, incluindo aí as relações de gênero, estabelecidas em cada época e lugar. Assim, propomos avaliar o estado da arte das discussões de gênero, a fim de perceber como as ciências da religião no Brasil têm absorvido as principais discussões acerca da categoria de gênero, nos últimos 17 anos. Também apresentaremos um estudo acerca da distribuição de gênero (masculino e feminino) no quadro docente, discente, e no corpo de funcionários dos Programas de Pós-Graduação em Ciências da religião, a fim de perceber se há ausência ou invisibilização da atuação de mulheres (levaremos em consideração para definição de mulheres a autoatribuição a essa categoria e como ela aparece nos documentos oficiais), em função da opressão histórica de gênero.

Como metodologia de pesquisa, utilizam-se como fonte de dados os sites dos respectivos Programas de Ciências da Religião, verificando junto ao programa as dissertações e teses defendidas que estão registradas no banco de dados das respectivas universidades por intermédio do sistema de publicação eletrônica de teses e dissertações (TEDE). Também o site da ANPTECRE forneceu as informações dos Programas de Pós-Graduação em Ciências da Religião. Para a análise, optamos por bibliografias que revelem o status da pesquisa na atualidade. Foram levantadas 181 dissertações e teses de doutorado correspondentes ao período de 2000 a 2017. ${ }^{1}$ Dessas pesquisas, 134 (74\%) foram pesquisas defendidas por mulheres e 47 realizadas por homens (26\%).

O número de pesquisas realizadas nos Programas de Ciências da Religião é maior que essas pesquisas que foram levantadas pelos autores. Muitas delas não estavam disponibilizadas para o público. Outras ainda não estão catalogadas no site da universidade ou biblioteca, e tivemos um Programa que não disponibilizou informações sobre as dissertações defendidas - a saber: a FUV-Faculdade União de Vitória. 
O conceito de Ciências da religião foi proposto por Max Müller (1823-1900), e deu origem a uma área acadêmica que busca esclarecer a experiência humana do sagrado. No Brasil, o estudo surge como Pós-Graduação, reunindo cientistas de diversas áreas, numa busca de multidisciplinariedade no olhar fenomenológico das práticas religiosas e institucionais, muitos deles advindos da teologia que até então dominava o espaço universitário brasileiro, quando se tratava de estudar as religiões (MENDONÇA, 2008, p. 240).

O debate acerca das diferenças e distinções entre homens e mulheres, historicamente, já figurava no plano político, por meio da militância feminina das mais variadas formas e ações durante o século $\mathrm{XIX},{ }^{2}$ desde a luta pelo abolicionismo e pelo sufrágio universal, a literatura feminista e a relação do trabalho com os espaços público/privado demarcados então por questões de gênero. A constituição da história das mulheres como campo de conhecimento se processou em relação direta com a atuação do movimento feminista ${ }^{3}$ das décadas de 1960 e 1970, quando então surge na década de 1980 a categoria de gênero.

Simone de Beauvoir (1980) e Betty Friedan (1971) são precursoras fundamentais desse movimento, que serviu de base para a historiadora

\footnotetext{
Não queremos aqui desconsiderar os traços antigos e eloquentes deixados por Christine de Pisan (1364-1430), Apha Behn (1640-1680), Olympe de Gouges (1745-1793), Mary Wollstonecraft (1759-1797), FloraTristan (1803-1844), Elizabeth Cady Stanton (1815-1902) e Susan B. Anthony (1820-1906), para citar apenas alguns nomes que conseguiram passar à posteridade a expressão de reinvindicações que concernem à igualdade, apenas enfatizar que esse fenômeno se evidencia com mais afinco a partir do século XIX, quando as barreiras, sanções institucionais e estruturais presentes em ordens sociais, profundamente androcêntricas, começam a ser desmontadas.

3 O movimento e os estudos feministas não são únicos, tampouco homogêneos. Segundo Descarries (2000), há pelo menos três correntes do feminismo. A primeira seria o Feminismo Igualitário ou Universalista que liderou o ressurgimento do movimento nos anos 60 e fomentou a adoção de uma questão das mulheres; atualmente, continua a fundamentar a ação de um grande número de organizações feministas e de organismos governamentais e sindicais. A segunda corrente é o Feminismo Radical, que ocupa uma grande parte do espaço teórico dos anos 70 e propõe uma leitura feminista das relações sociais de sexo nos termos de dominante e dominada. Algumas tendências dessa corrente apresentam-se sob diversas formas, ao longo dos anos 80 . Podem ser reagrupadas em torno de um movimento, muitas vezes, designado como Feminismo Global, que Descarries chama de Feminismo Solidário. Enfim, a terceira corrente é a do Feminismo da Feminitude (fémelleité), que se desenvolve paralelamente às diferentes tendências do feminismo Igualitário e Radical.
} 
norte-americana Joan Scott (1995), em 1986, escrever o artigo intitulado Gênero: uma categoria útil de análise histórica, e que aqui no Brasil só foi publicado em 1995, onde consegue sair da dualidade sexo (natureza) e gênero (cultura), até então pautada pelos estudos feministas. No artigo, Joan Scott apresenta a categoria gênero e parte do pressuposto de que não há separação entre saber e poder e que o gênero é um saber sobre as diferenças sexuais que implica relações de poder, que fazem sentido para as pessoas. Daí em diante, autoras como Judith Butler, Gayatri Spivak, Jenny Sharpe, Mrinalini Sinha, Cristiane Lasmar, Tânia Navarro Swain, Francine Descarries, entre tantas outras, passam a debater o assunto.

Essa constatação implica assumir que a noção de sujeito, embora marcada por particularidades que se pretendiam universais, a partir do projeto Iluminista para a Modernidade e, na medida em que pretendiam universalizar as especificidades do homem branco, heterossexual e detentor de propriedades, se tornava uma categoria normativa e opressora, para usarmos a definição de Judith Butler (1997) e tornava a mulher e outros grupos oprimidos ausentes ou invisíveis, para usarmos a caracterização dada por Joan Scott (1995). Na perspectiva do feminismo pós-colonial de Gayatri Spivak (2010), “os subalternos não podem falar" e, por isso, o "sujeito historicamente, emudecido da muIher subalterna" em particular, estava inevitavelmente fadado a ser ou mal compreendido ou mal representado segundo os crivos e interesses particulares de quem tem poder para representar. Dessa forma, o gênero ao dar sentido para as relações entre os sexos não só as diferencia, como também as hierarquiza, e isso se constitui numa maneira dualista e engessada do pensar ocidental. Desconstruir esse pensamento e essas relações possibilita novas relações entre os sexos e, por consequência, novas formas de organizar as sociedades, o saber e o poder.

Cabe ressaltar que outra contribuição dessas teorias é a constatação de que a representação da mulher enquanto categoria estável e permanente, fixada numa essência, é ficcional, como alerta Judith Butler (1997). Partindo de uma perspectiva pós-estruturalista, ancorada em Michel Foucault (1985) e Jacques Derrida (1973), Judith Butler (1997) entende que não existe "a mulher" antes de sua formação dis- 
cursiva, seria a própria representação que produz os sujeitos que ela supostamente pretende apenas representar. Desse modo, o gênero seria construído performativamente, ou seja, ele toma corpo não por uma ação única, mas por meio de reiterações, de tal sorte que ele é sempre uma citação, incapaz, como tal, de repetir o original ausente e inexistente. O gênero é produção ritualizada, performance. Assim, na esteira de Judith Buttler (1997), buscamos flexibilizar a categoria "muIher", passando do sujeito abstrato ao sujeito concreto, reconhecendo assim que se a mulher não existe como universal, isto é, como sujeito uno, há, no entanto, mulheres concretas, heterogêneas, múltiplas, que compartilham, cada uma ao seu modo, uma série de opressões, e que podem, então, no mínimo como estratégia de ação política, compartilhar também de um objetivo comum.

No caso das Ciências da Religião, essa desconstrução passa pela revisão das crenças religiosas e pela dissolução da desigualdade de gênero que está historicamente instalada no seio das instituições religiosas e que são transmitidas de geração a geração.

Nem todas as pesquisas que tiveram como objeto os sexos na sua dinâmica religiosa utilizaram a categoria de gênero proposta por Joan Scott (1995) ou Judith Butler (1997) como análise científica, mas muitas das pesquisas apontaram para uma desigualdade de gênero nas religiões e nas relações institucionais.

\section{DISTRIBUIÇÃO DOS GÊNEROS MASCULINO-FEMININO NOS PROGRAMAS DE PÓS-GRADUAÇÃO EM CIÊNCIAS DA RELIGIÃO E TEOLOGIA NO BRASIL}

Segundo dados da Associação Nacional de Pós-Graduação e Pesquisa em Teologia e Ciências da Religião (ANPTECRE), referentes ao ano de 2015, existem 12 programas de Pós-Graduação em Ciências da Religião no Brasil, sendo sete deles localizados na região sudeste, três na região nordeste, um na região norte e um na região centro-oeste. Destes, apenas um Programa é ofertado no modelo de mestrado profissional, a Faculdade Unida de Vitória-FUV, no Espírito Santo. Três desses programas realizam-se em universidades públicas no âmbito federal 
(Universidade Federal de Juiz de Fora - UFJF, Universidade Federal da Paraíba - UFPB e Universidade Federal de Sergipe - UFS), e um é ofertado por uma universidade estadual, no Pará (Universidade do Estado do Pará - UEPA) e os demais são oferecidos por universidades particulares de denominação religiosa, sendo cinco universidades católicas, duas presbiterianas e uma metodista.

Ao verificar o panorama dos docentes existentes nesses programas, percebe-se já na estruturação dos cursos uma desigualdade de gênero, como podemos ver no quadro a seguir:

\begin{tabular}{|l|l|l|l|l|}
\hline UNIVERSIDADE & $\begin{array}{l}\text { Docentes } \\
\text { Homens } \\
\text { Permanentes }\end{array}$ & $\begin{array}{l}\text { Docentes } \\
\text { Homens } \\
\text { Colaboradores }\end{array}$ & $\begin{array}{l}\text { Docentes } \\
\text { Mulheres } \\
\text { Permanentes }\end{array}$ & $\begin{array}{l}\text { Docentes } \\
\text { Mulheres } \\
\text { Colaboradoras }\end{array}$ \\
\hline UFJF & 17 & 2 & 1 & 1 \\
\hline PUC/Goiás & 9 & & 3 & \\
\hline PUC/MG & 9 & & 1 & \\
\hline PUC/SP & 10 & & 1 & \\
\hline UEPA & 8 & & 4 & \\
\hline UNICAP & 13 & & 1 & \\
\hline UMESP & 13 & & 2 & \\
\hline MACKENZIE & 6 & & 2 & \\
\hline UFPB & 7 & & 7 & \\
\hline UFS & 7 & 5 & 0 & \\
\hline PUC-CAMPINAS & 8 & & 2 & \\
\hline FUV & 14 & & 1 & \\
\hline
\end{tabular}

Fonte: http://www.anptecre.org.br/index.php?pagina=formulario\&tela=28

Como se pode observar, as mulheres estavam em número menor que os homens nos Programas de Pós-Graduação em Ciências da Religião. Em dois programas, não havia qualquer mulher docente e apenas na Universidade Federal da Paraíba se encontrou uma paridade de gênero, sendo sete docentes homens para sete docentes mulheres. Esse quadro se ampliou para as mulheres quando se percebe que havia ainda três docentes mulheres como professoras visitantes. Em dois programas, não existiam professoras mulheres no quadro docente, como na Universidade Federal de Sergipe e na Faculdade União de Vitória. 
Visitando o site atual do Programa, percebeu-se que o mesmo quadro se mantém na Universidade Federal de Sergipe, sem nenhuma mulher docente nessa Pós-Graduação. Mesmo programas mais antigos como a PUC/SP (1978), a UMESP (1979) e a UFJF (1993) também não priorizam um quadro mais equitativo de gênero. Isso reflete quando se analisa os cargos de poder. Nessa época, apenas um programa tinha mulheres na coordenação, que era a PUC de Goiás, com a professora Irene Dias de Oliveira. O mesmo reflexo se repetiu ao contrário, quando se observou os cargos de secretaria dos programas, pois destes 12 programas, apenas dois portavam homens na secretaria (UFJF e PUC Goiás), os demais eram todos com mulheres.

Esse quadro mudou em pouca coisa em dois anos. Em 2017, na UFPB se manteve a paridade de gênero, e, atualmente, há uma coordenação mista composta pela Profa. Dra. Dilaine Soares Sampaio e pelo Prof. Dr. Fabrício Possebon. Na UNICAP, a Profa. Dra. Zuleica Dantas Pereira Campos é a atual coordenadora. A FUV incorporou uma mulher em seu quadro docente, a Dra. Claudete Beise Ulrich, que vem de uma larga experiência e produção acadêmica na teologia feminista e nos estudos de gênero.

Dessas mulheres professoras, destacam-se duas docentes em São Paulo, sendo uma lotada na PUC de São Paulo, a professora Maria José Fontelas Rosado-Nunes, que produziu ao longo de sua vida profissional mais de 40 artigos em revistas nacionais e internacionais, bem como, cerca de 50 capítulos para livros e nove livros publicados, todos cruzando as questões do feminismo com religião. Segue essa estatística a professora Sandra Duarte de Souza, docente da Universidade Metodista de São Paulo, que foi orientanda de Maria José Fontelas Rosado-Nunes e que já escreveu 34 artigos, 21 capítulos de livros e seis livros, a maioria explorando a temática de gênero e seus desafios no contexto cultural religioso brasileiro.

Ainda no programa da UMESP, desde 1998, atua a professora Lieve Troch, da Radboud Universiteit na Holanda, que é uma professora e feminista, que articula os estudos feministas com religião e práticas religiosas aqui no Brasil. Ela tem orientado dissertações e teses que articulam temas ligados aos estudos de feministas e de gênero. 
Na PUC Goiás, encontra-se a professora Ivoni Richter Reimer, com mais de 40 livros publicados e 90 artigos, a maioria trazendo reflexões sobre as Sagradas Escrituras e gênero, ou ensinando a ler e interpretar as Sagradas Escrituras com a categoria de gênero. Também se encontra nessa mesma instituição a docente Carolina Teles Lemos, que foi orientanda da professora Maria José Fontelas Rosado-Nunes, com uma larga experiência em pesquisa de gênero e religião, com publicações sobre o feminismo, as mulheres e relações de gênero.

Na UFPB, localiza-se a professora Fernanda Lemos, que fez seu mestrado em Ciências da Religião com a temática de gênero, trabalhando com masculinidades sob orientação da professora Sandra Duarte de Souza na UMESP, e tem um livro publicado nesse assunto. Já a professora Suelma de Souza Diniz foi orientanda da professora Lieve Troch, e fez seu mestrado na UMESP. Trabalha, atualmente, com ecofeminismo na UFPB.

Na UNICAP, a professora Zuleica Dantas Pereira Campos é estudiosa das religiões afro-brasileiras, articulando muitas pesquisas com a questão de gênero.

Na PUC-Minas, em Belo Horizonte, constava em 2015 que havia uma docente mulher no quadro dos professores. Na época, estava a professora Anete Roese, que também tem uma vasta produção de gênero e religião. Em 2016, ela se retira do Programa de Ciências da Religião na Pontifícia Universidade Católica de Minas Gerais, sendo substituída pela professora Gisele do Prado Siqueira, que não tem produções nas questões de gênero. A professora Claudete Beise Ulrich vem de São Leopoldo, onde fez seu mestrado e doutorado em teologia, na Escola Superior de Teologia (EST). Suas publicações e estudos estão voltados para educação, religião e gênero.

Nas demais instituições, não se encontram docentes mulheres no quadro permanente ou de colaboradores.

\section{PANORAMA DOS PROGRAMAS DE PÓS-GRADUAÇÃO EM CIÊNCIAS DA RELIGIÃO E OS ESTUDOS DE GÊNERO}

Os programas de Ciências da Religião, no Brasil, são relativamente novos. O primeiro foi criado em 1978, em São Paulo, na Pontifícia Universidade Católica com o mestrado e, em 2002, passou a oferecer também 
o doutorado. O Programa mantém ativas duas revistas especializadas, a REVER - Revista de Estudos da Religião, e a Último Andar, esta específica para a publicação de artigos produzidos pelo corpo discente. A REVER foi lançada em 2001 como uma revista eletrônica (e-journal), e a partir de 2011 é simultaneamente publicada em forma digital e em forma impressa.

Na base de dados da PUC/SP, estão catalogadas 429 teses de doutorado e dissertações de mestrado, sendo que 35 dissertações e oito teses versam sobre o tema de gênero e/ou mulheres.

O Programa de Pós-Graduação em Ciências da Religião de São Bernardo, que se originou em 1979, no antigo Instituto Metodista do Ensino Superior, localizado em São Bernardo do Campo, em São Paulo, é o Programa que mais produziu dissertações de mestrado e teses de doutorado para o Brasil, sendo 626 dissertações de mestrado e 208 teses de doutorado. Entre 1980 a 2000, foram 197 dissertações defendidas no Programa, destas 21 versavam sobre o tema da condição da mulher nas diversas experiências e instituições religiosas. Inicialmente, esse tema empolgou mulheres que se matricularam no Programa e que foram incentivadas, principalmente, pelo professor Milton Schwantes e pela professora Maria José Fontelas Rosado-Nunes, que, na época, estava como docente do Programa, eles impulsionaram pesquisas sobre o tema, bem como, muitos ensaios articulando exegese bíblica na perspectiva de gênero que sobressaíram nesse momento.

A partir de 2001, os temas se voltam mais para a teologia feminista e para os estudos de gênero. De 2001 a 2017, defenderam-se 429 dissertações, sendo 46 voltadas para o tema das mulheres e/ou gênero. Em relação às teses, encontram-se 24 teses de doutorado dentro da perspectiva temática do gênero. O Programa mantém cinco revistas, sendo a revista Estudos de Religião e a Mandrágora no modo impresso e três eletrônicas: a Convenit, a Correlatio e a Orácula, além disso, o Programa mantém um portal eletrônico para a Bibliografia Latino-Americana. A revista Mandrágora, que tem seu primeiro número publicado em 1994, é uma publicação do Grupo de Estudos de Gênero e Religião Mandrágora/ NETMAL, e é a única revista especializada para os estudos de Gênero e Religião. 
Em Minas Gerais, existem dois Programas de Pós-Graduação direcionados aos estudos das religiões. O primeiro deles está na Universidade Federal de Juiz de Fora. Trata-se do Programa de Pós-Graduação em Ciência da Religião, que iniciou suas atividades em 1993, fruto do Departamento de Ciência da Religião, existente na Universidade desde 1969, oferecendo disciplinas eletivas para os cursos de graduação da UFJF. Esse departamento foi o primeiro a ofertar estudos fenomenológicos da religião numa universidade pública. Na década de 1970, funcionou por alguns anos o curso de graduação, mediante ingresso com vestibular, experiência que foi interrompida posteriormente com a ditadura militar. No ano 2000, iniciaram-se as atividades de doutorado, que tem 108 teses defendidas em 17 anos, sendo que quatro delas trazem mulheres como objeto de estudo, mas não se utiliza a categoria de gênero como análise da religião. A respeito das dissertações, tem-se 291 dissertações defendidas no Programa entre os anos de 1995 a 2017, mas o repositório tem apenas 185 dissertações na base de dados (a partir do ano 2000). Destas encontramos 14 dissertações que versam a respeito do tema das mulheres ou teologia feminista. Existem pesquisas acerca do tema, não catalogadas no repositório, como uma dissertação sobre a condição feminina no século XIX, trazendo a figura da madre Germana, uma análise das mulheres na Igreja Batista, e uma pesquisa sobre a teologia feminista de Ivone Gebara. O Programa possui duas revistas a NUMEN e a SACRILEGENS.

Outro Programa em Minas Gerais está na Pontifícia Universidade Católica de Minas Gerais. A investigação sobre os fenômenos religiosos surge a partir do interesse em formar professores para o ensino religioso nas escolas, inicialmente com um programa de pós-graduação lato sensu e depois, em março de 2008, inicia-se a primeira turma de Pós-Graduação em Ciências da Religião no modelo Stricto Sensu com o mestrado e somente em 2015 nasce o doutorado nessa mesma área. Na base de dados da Universidade, constam 116 dissertações defendidas entre os anos de 2009 a 2017, sendo que cinco delas abordam temas relativos ao gênero: a primeira, investiga as mulheres nas festas do Congo, em Minas Gerais; a segunda, estuda o masculino, analisando a prática atual de terço dos homens; a terceira, faz uma análise das abordagens feministas nas ciências da religião e a quarta apresenta uma pesquisa acerca 
das relações de gênero e religião nas igrejas evangélicas fundadas por mulheres. Também há uma dissertação sobre homossexualidade. No doutorado, as pesquisas encontram-se em andamento, mas não temos registro de quais delas se referem ao tema do gênero. O Programa tem a revista INTERAÇÕES e a revista HORIZONTE.

No centro-oeste do Brasil, a Pontifícia Universidade Católica de Goiás, com sua sede em Goiânia, tem o Programa de Pós-Graduação Stricto Sensu em Ciências da Religião, cujas atividades se iniciaram em março de 1999 com o mestrado, que tem 250 dissertações registradas na Biblioteca Digital de teses e Dissertações, sendo que 35 delas são pesquisas sobre mulher e/ou gênero. O doutorado teve seu início em 2007, tem 58 teses defendidas e 14 destas remetem ao tema de gênero e mulheres. O Programa tem a revista científica intitulada CAMINHOS.

Na região norte do Brasil, em Belém do Pará, a arquidiocese fez um pedido para a implantação de um Curso de Licenciatura em Ciências da Religião, a fim de que os diplomas dos cursos de teologia da Arquidiocese fossem equiparados pelo mesmo. Assim, em outubro de 1999, foi criado o curso que realizou seu primeiro vestibular em 2000 para licenciatura em Ciências da Religião. Dez anos depois, em outubro de 2010, era aprovado pela Capes o mestrado em Ciências da Religião (DOUGLAS, 2012, p. 308). O Programa possui um periódico multidisciplinar chamado OBSERVATÓRIO DA RELIGIÃO, apresentando artigos pertinentes aos estudos da religião. No site do Programa estão registradas 25 dissertações de mestrado, das quais quatro se referem aos estudos de gênero. O Programa mantém a revista OBSERVATÓRIO DA RELIGIÃO.

Na região nordeste, encontra-se um Programa de Ciências da Religião da Universidade Católica de Pernambuco-UNICAP, trazendo o mestrado que existe desde 2004 e que foi o pioneiro no Nordeste. Em 2015, deu-se início aos estudos de doutorado no Programa. Foram encontradas 154 dissertações registradas pelo Programa na Biblioteca Digital de teses e dissertações, sendo dez delas voltadas para o tema de gênero. O Programa mantém a REVISTA DE TEOLOGIA E CIÊNCIAS DA RELIGIÃO, impressa e on-line, e a revista PARALELLUS, que desde 2010 se mantém como uma publicação dos estudantes do Mestrado em Ciências da Religião da UNICAP. 
Ainda no Nordeste, encontram-se dois Programas de Ciências da Religião em universidades públicas. O primeiro deles se encontra no Estado da Paraíba. Localizado na UFPB, o Programa foi criado em 2006, sendo fruto do Grupo de Pesquisa em religião e religiosidade - RELIGARE - existente desde 1996 e que promoveu o ensino de disciplinas nas Ciências Sociais, cursos de extensão, encontros e cursos de especialização. Em 2007, o mestrado teve seu início e, em 2015, os estudos de doutorado passaram a ser oferecidos. O programa de mestrado tem registradas 146 dissertações, sendo que 19 delas abordam a temática de gênero. O Programa mantém, também, duas revistas: a RELIGARE e a DIVERSIDADE RELIGIOSA, voltadas para os discentes e de publicação eletrônica.

O programa mais recente em universidade pública é o Programa de Pós-Graduação em Ciências da Religião da Universidade Federal de Sergipe. Entrou em vigor no ano de 2014, com o mestrado, e tem 15 dissertações de mestrado defendidas. Destas, apenas duas trazem o tema de gênero, analisando a questão do feminino. Numa delas, a autora analisa imagens femininas na alquimia, no século XVI, e o simbolismo da mesma, na perspectiva jungiana, revelando que o feminismo se refere a corpo, sexo, maternidade. A segunda analisa o discurso sobre feminilidade apresentada pela Igreja Católica para as mulheres que se voluntariam para trabalhar na pastoral da criança e percebe que o discurso reforça a ideia da maternidade, mas que as mulheres desafiam esse paradigma se empoderando nas comunidades como lideranças sociais. Há ainda marcada uma defesa de dissertação com o título Ideologia de gênero, novo martelo das feiticeiras: um histórico da cruzada contra gênero empreendida pelo campo católico conservador.

O fato de existir três dissertações no Programa que tem apenas homens na composição do quadro docente não inviabiliza pesquisas com análises de gênero. Alguns homens docentes têm sensibilidade acadêmica para os trabalhos de gênero. Tivemos acesso apenas a uma dissertação de Micaela Oliveira Eugênio Costa, intitulada Corpos, cruzes e ressurreições: um estudo fenomenológico das experiências do cotidiano de mulheres líderes da Pastoral da Criança. Nessa pesquisa, orientada pelo Dr. Romero Junior Venâncio Silva (aliás, o orientador das três únicas dissertações com análise de gênero no Programa), a autora faz 
uma análise dos discursos tradicionais da Igreja católica que impõem uma feminilização das líderes da Pastoral da Criança na arquidiocese de Aracaju e cruza com entrevistas realizadas com essas líderes, revelando que apesar dos discursos patriarcais impostos pela instituição, as mulheres vão muito além desses discursos na sua prática cotidiana, revelando líderes sociais empoderadas pela comunidade.

A análise mostra que os discursos de gênero não têm tanto impacto sobre essas mulheres quando as mesmas, no campo de ação social, vão tecendo relações para além desses estereótipos reproduzidos pela instituição e pela sociedade, revelando assim mulheres que recriam suas histórias no cotidiano e que vão além dos discursos e práticas patriarcais. A autora utiliza a categoria de gênero como análise a partir do trabalho de Joan Scott, e traz como autoras para a análise Ivone Gebara, Maria José Rosado-Nunes, Simone de Beauvoir, Mary Hunt, Neuma Aguiar, Guacira Lopes Louro e outras autoras/es que trabalham com o feminismo e a categoria de gênero.

No mundo presbiteriano, também há a preocupação com a formação de professoras e professores para o ensino religioso e os estudos da religião. Em São Paulo está em funcionamento, desde 2002, o Programa de Pós-Graduação em Ciências da Religião (PPG/CR) da Universidade Presbiteriana Mackenzie (UPM). O Programa mantém a REVISTA DE CIÊNCIAS DA RELIGIÃO: HISTÓRIA E SOCIEDADE que até 2007 tinha periodicidade anual e passou para semestral em 2008.

A inclusão das Ciências da Religião no Programa de Pós-Graduação da Universidade Presbiteriana Mackenzie tem ligação com a memória e a tradição do cristianismo, bem como, da influência do pensamento religioso cristão do protestantismo reformado, tanto nas instituições sociais, como no cotidiano das pessoas. Nesse sentido, a abordagem das Ciências da Religião na UPM dialoga com a Teologia Reformada, a História Social das Religiões, a Teoria Sociológica e a Sociologia do Conhecimento, a Antropologia da Religião e a Psicologia Social das Religiões. O Programa tem cadastradas 75 dissertações de mestrado, sendo que três delas versam sobre a temática de gênero. Constata-se, também, que todas essas pesquisas foram orientadas por professores homens, o que revela que não precisa ser mulher para trabalhar com a categoria 
de gênero. O mesmo se dá entre os alunos, pois dois pesquisadores da temática são homens. Em geral, pesquisam o nexo entre religiões orientais e ocidentais em relação às assimetrias de sexos e igualdade de gênero. Interessante notar que nenhuma dessas pesquisas utilizou como guia bibliográfico a teologia feminista ou mesmo as publicações de gênero, amplamente produzidas nas academias estrangeiras e nacionais. Isso mostra uma sensibilidade para a desigualdade de gênero existente nas instituições religiosas, mas não são produções que buscam dialogar com os estudos feministas e teorias de gênero.

Outra instituição do mundo protestante é o Mestrado em Ciências das Religiões da Faculdade Unida de Vitória, também de origem presbiteriana. Trata-se do primeiro Mestrado Profissional na área, não apenas no Estado do Espírito Santo, mas em todo o Brasil, tendo sido regulamentado em 2011.

A estrutura do Programa consiste em aulas presenciais em regime intensivo: quatro encontros de duas semanas cada um, nos meses de janeiro e julho, na sede da Faculdade Unida em Vitória-ES, culminando com o Trabalho de Conclusão do Curso, conforme a regulamentação do Mestrado Profissional pela CAPES. O Programa tem a revista UNITAS Revista Eletrônica de Teologia e Ciências das Religiões para divulgação de suas pesquisas e para diálogo com outras universidades e a revista REFLEXUS - Revista Semestral de Teologia e Ciências das Religiões, ambas com periodicidade semestral.

Não tivemos acesso às dissertações ou trabalho de conclusão de curso da faculdade, não sendo possível analisar essas mesmas pesquisas.

Por fim, no interior de São Paulo, na região de Campinas, tem-se o Programa de Pós-Graduação em Ciências da Religião, criado, também, em 2014. Tem apenas 18 dissertações defendidas e nenhuma delas tem pesquisa em feminismo ou gênero. O Programa tem um periódico intitulado REFLEXÃO.

Dessa forma, produziram-se, nestes 40 anos de existência de Programas de Pós-Graduação em Ciências da Religião, por volta de 2.519 (90,25\%) dissertações e teses, sendo que 245 (9,75\%) dessas pesquisas são referentes aos estudos da mulher, feminista e/ou de gênero no Brasil, abordando as mais diversas religiões e práticas religiosas, analisando 
as relações entre os sexos, os discursos e representações produzidas que condicionam homens e mulheres a determinados comportamentos e, muitas vezes, restringindo-os em sua liberdade. O número de pesquisas sobre a temática de gênero ainda é muito pequeno diante da realidade sociorreligiosa que se tem no país. Contudo, essas são pesquisas significativas, que merecem ser publicadas e propagadas para o conhecimento de toda a sociedade brasileira, e que abrem diálogo multidisciplinar e profícuo com a academia e com toda a sociedade.

\section{Teses e dissertações}

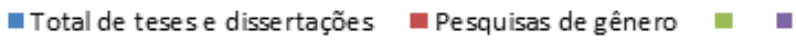

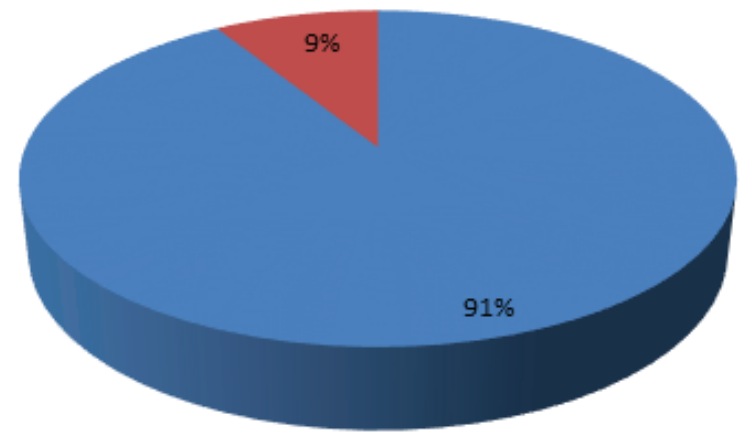

Fonte: Gráfico elaborado pelos/as autores/as deste artigo.

\section{OS OBJETOS DE ESTUDO NAS PESQUISAS DE GÊNERO E RELIGIÃO}

Constata-se que as mulheres se interessam muito mais pelas pesquisas de gênero que os homens. Talvez esse fato confirme a tese de Hanna Pitkin (apud RABENHORST; CAMARGO, 2013), de que a representação só pode ser feita se os representantes tiverem absolutamente os mesmos interesses dos representados, indicando o paradoxo da representação do outro. ${ }^{4}$ Afinal, como indica Neil Lazarus (2006), quem representa

4 O paradoxo, como nos alerta Eduardo Rabenhorst e Raquel Camargo (2013), consiste no fato de que o ato de representar é tornar presente aquilo que está ausente, se estaria, portanto, diante de uma impossibilidade. Afinal, de que maneira é possível tornar presente o que está ausente? 
em sentido político não pode deixar de representar a si mesmo e ao outro no sentido do retrato, e invariavelmente corre o risco de usurpar o espaço alheio, ainda que por inadvertência.

Esse fato explica a ausência histórica de estudos sobre as mulheres, uma vez que elas estavam também ausentes da ciência em função da dominação e opressão de gênero. Assim, é possível perceber que os estudos de gênero nascem das lutas feministas cunhadas ao longo do século XIX e XX, na Europa e na América, que influenciaram o Brasil. O confronto desses movimentos com as realidades sociais foram, muitas vezes, dolorosos, uma vez que na construção ocidental dessas sociedades a mulher ocupava papéis inferiores aos homens.

Logo, romper com a mentalidade hierárquica dos papéis de gênero e polarizar as mulheres no espaço público foram os grandes avanços obtidos das lutas feministas. Na academia brasileira, os estudos de gênero como conhecemos hoje é fruto de reflexões feministas, muitas delas rechaçadas com repúdios ou descréditos pela estrutura patriarcal das universidades. A tensão entre as representações sociais do feminismo e a identificação das mulheres e homens com algumas propostas feministas reside na dificuldade de desconstrução de alguns paradigmas relacionados ao que Pierre Bourdieu (2009) chama de habitus masculino, ou seja, um modo de agir masculino, já consolidado e que impediria a desnaturalização de algumas construções sociais, como o casamento ou a maternidade.

Não obstante o sucesso obtido pelas lutas feministas que colocaram nas universidades as mulheres (seja como alunas, seja como professoras e gestoras), percebeu-se que a estrutura patriarcal das universidades

\footnotetext{
A única possibilidade, parece, seria fazê-lo alegoricamente, no sentido exato da palavra: "dizer o outro". A representação, no entanto, e é isso que vem a torná-la problemática, não pretende apenas "dizer o outro", mas "dizer pelo outro". O representante é, assim, ao mesmo tempo um "lugar-tenente" e um "porta-voz". Isso implica dizer que inicialmente, no ato de representar, deve sempre existir uma distância entre o elemento que representa ou substitui e aquilo que é representado ou substituído. Tal dissociação, na verdade, é a razão mesma de ser da representação. Do contrário, haveria uma fusão entre o representante e o representado, que tornaria a representação inútil. Por sua vez, Gayatri Spivak (2010) salienta que a representação alheia implica o fato de que os grupos subalternizados são sempre intermediados pela voz de outrem, isto é, por aqueles que possuem o poder de representar e de descrever, e que controlam, assim, a maneira como os que não detêm idênticos poderes serão vistos.
} 
não se modificara. As mulheres estavam presentes em número bem menor nos Programas de Pós-Graduação e, muitas vezes, para estarem ali tinham que se revestir de um sujeito universal masculino dentro de papéis já conformados para homens e mulheres pela organização social. As mulheres realmente tinham conquistado espaço na universidade, mas não tinham a força necessária para serem elas mesmas em suas funções, sem terem que assumir os mesmos comportamentos masculinos que os homens exerciam.

O mesmo acontecia em outras esferas da vida social, onde muitas mulheres precisaram se revestir de homens para poder ocupar seus espaços e agir como eles. No Brasil, Rose Marie Muraro fez seu desabafo por intermédio do livro Os seis meses em que fui homem, quando tentou uma candidatura para deputada constituinte: "Sem querer, eu já estava jogada dentro do mundo da decisão que é o mundo masculino. Os últimos seis meses de 1986 foram exatamente os seis meses em que fui homem" (MURARO, 1991, p. 112). No entanto, como salienta Gayatri Spivak (2010), há sempre algo de potencialmente subversivo na reiteração parcial de um discurso, pois a repetição pode produzir efeitos inesperados exatamente a partir do corte ou fragmentação daquilo que foi dito. A apropriação é capaz de incidir, como uma espécie de refluxo, sobre a própria forma como o discurso dominante se configurou originalmente.

Diante de todas essas dificuldades, o uso da categoria de gênero se tornou uma possibilidade de empoderar as mulheres, com todas as suas heterogeneidades e multiplicidades, que compartilham, cada uma ao seu modo, uma série de opressões, na academia, permitindo sua liberdade de pensamento e ação, na medida em que se questionava as relações de poder entre os gêneros.

A categoria de gênero veio para possibilitar a transformação das estruturas patriarcais e de mentalidades androcêntricas, pois questionava as relações instituídas entre os gêneros que constituíam poderes hierárquicos. Desconstruir essas relações assimétricas, milenarmente constituídas na história e propagadas pelas crenças, era a proposta do uso do gênero enquanto categoria analítica. Com essa perspectiva, pesquisas e livros foram publicados na perspectiva de dar continuidade 
aos estudos feministas, agora ampliando para a possibilidade de criar novas relações entre os gêneros.

Para isso, era preciso empoderar as mulheres, pois era lá que os homens estavam e era preciso encontrá-los para iniciar um diálogo profícuo. De fato, muitos homens começaram a se reunir e a escrever, percebendo-se, também, vítimas da sociedade patriarcal, na medida em que os papéis masculinos a eles atribuídos também se constituíam num fardo pesado para eles. Constatou-se, assim, que a sociedade patriarcal produzia papéis de gênero para homens e mulheres, impedindo de fato que emergisse o ser humano desatrelado desses papéis e livres para pensar e agir. As pesquisas em torno do masculino têm dado essa contribuição na discussão sobre identidades de gênero.

Nos Programas de Ciências da Religião nas universidades brasileiras não foi diferente. Inicialmente, encontramos os homens, os quais vinham empoderados de suas instituições religiosas. Eram padres e pastores organizando esses Programas, seja no interesse institucional de reconhecer as ciências teológicas (marginalizada pela tradição positivista), seja na perspectiva de trazer o tema da religião e religiosidade brasileira para a relevância acadêmica, uma vez que culturalmente a religião e a religiosidade fazem parte integrante da formação social dos brasileiros. Era preciso entender cada vez mais como o Brasil constituía sua identidade no arcabouço religioso e como isso influía em seus comportamentos existenciais e sociais.

O início formal das Ciências da Religião se deu na PUC-SP e na Metodista. Eu me lembro muito bem de que um dos nossos objetivos era inscrevê-las no quadro das ciências brasileiras, ou seja, no MEC, no CNPq e na CAPES, mostrando que se tratava de um corpo de conhecimentos mais específicos, com um estatuto formal (MARQUES; ROCHA, 2007, p. 195).

Aos poucos, as mulheres foram entrando no Programa para se formarem. A Universidade Metodista teve uma projeção significativa nesse aspecto, uma vez que em seu X Concílio Geral da Igreja Metodista, realizado em 20 de julho de 1970, em Belo Horizonte, Minas Gerais, se decidiu que "as ordens na Igreja Metodista são duas: presbiteral e 
diaconal, constituídas, respectivamente, de presbíteros e diáconos, sem distinção de sexo" (RIBEIRO, 2014, p. 129). Isso fez que três mulheres aproveitassem a oportunidade, se mudando para o seminário teológico da Faculdade Metodista localizada em Rudge Ramos, em São Bernardo do Campo, e quatro anos depois seria ordenada a primeira presbítera da Igreja Metodista. Com o tempo, a Faculdade de Teologia criou seu curso de mestrado em Teologia, que se torna o atual Programa de Pós-Graduação em Ciências da Religião (MARQUES; ROCHA, 2007, p. 208).

Estudantes que tiraram seus títulos de mestras e doutoras hoje se encontram trabalhando em vários Programas de Pós-Graduação em Ciências da Religião e outras em curso de graduação em Ciências da Religião ou áreas de humanas.

Os temas e objetos de pesquisa estudados por homens e mulheres na categoria de gênero, encontrados nas dissertações e teses avaliados nesta pesquisa, podem ser organizados desta forma:

1. Mulheres e suas representações sociais, bem como, discursos produzidos pela sociedade, pela literatura, pelos documentos das instituições religiosas, análise de discurso sobre família, aborto, corpo feminino, e imagens difundidas pela produção patriarcal sobre as mulheres e os homens (32 pesquisas);

2. Mulheres e curas, abrangendo mulheres com práticas religiosas populares, bem como, mulheres que com sua fé enfrentaram doenças ou curaram doenças; mães cuidadoras; parteiras; práticas de enfermeiras e curandeiras; santas populares (19 pesquisas);

3. Mulheres na Bíblia, incluindo mulheres nos estudos dos apócrifos (29 pesquisas);

4. Mulheres na Igreja Católica, constando pesquisas sobre mulheres consagradas, nas romarias, nas devoções e cultura popular, nas pastorais e movimentos religiosos dentro da Igreja Católica (17 pesquisas);

5. Mulheres afrodescendentes, com análise da condição da mulher negra, suas representações sociais, suas práticas religiosas e estudando a mulher nas religiões afro brasileiras (15 pesquisas); 
6. Mulheres e seu confronto nos espaços de poder, abrangendo gênero e poder, ordenação de mulheres, poder familiar, muIheres na teologia, mulheres e suas dificuldades no presbitério ou pastorado feminino (14 pesquisas);

7. Mulheres e espiritualidade, trazendo o sagrado feminino; ou simplesmente as místicas, articulando espiritualidade e fé ou estudando a religião de WICCA pelas mulheres (12 pesquisas);

8. Mulheres protestantes ou pentecostais analisando seus cotidianos nas igrejas, trazendo histórias de vida, bem como, análise da condição feminina nessas igrejas (nove pesquisas);

9. Sexualidade e corpo, abrangendo abusos sexuais por pais de família ou padres, prostituição ou crianças interssexuais (sete pesquisas);

10. Masculino e poder masculino analisando papéis de gênero construídos para os homens ou devoções masculinas criadas para os homens, ou mesmo análise de doenças nos homens (sete pesquisas);

11. Homossexualidade nos seus mais variados aspectos (cinco pesquisas);

12. Violência de gênero (três pesquisas);

13. Mulheres em outras religióes, sendo no islamismo (seis pesquisas), no budismo (duas pesquisas), no hinduísmo (uma pesquisa) e no Vale do Amanhecer (uma pesquisa) totalizando 10 pesquisas;

14. Mulheres na luta social e operária (uma pesquisa);

15. Mulheres na prisão e sua fé (uma pesquisa).

Percebe-se o movimento que as pesquisas foram fazendo no Brasil. O "carro chefe" são as pesquisas que se propuseram a analisar discursos produzidos pelas instituições sobre os papéis femininos, a respeito dos comportamentos femininos, sobre as imagens construídas para o feminino por uma sociedade androcêntrica. Trata-se aqui de análises acerca do corpo, a sexualidade e seus usos, os abusos sexuais, os papéis designados ao feminino e suas representações. 
Seguem-se pesquisas voltadas para as práticas religiosas das muIheres que as fazem protagonistas de sua história, seja no plano popular, atuando como benzedeiras, parteiras e curandeiras, seja no plano institucional, onde atuam como mulheres devotas, trabalhadoras nas igrejas como obreiras, religiosas, pastoras, pastoralistas ou teólogas. Aqui se encontram mulheres cristãs e não cristãs.

O terceiro momento passou a focar as relações de gênero propriamente ditas, cruzando a condição da mulher com a condição dos homens existentes nas instituições religiosas, analisando o poder; a violência, a desigualdade de gênero, a relação com o sagrado em todas as suas esferas no confronto com uma mentalidade de superioridade masculina. Nesse campo encontram-se, ainda tímidas, alguns trabalhos de pesquisa em torno do masculino e dos papéis de identidade de gênero dedicado aos homens, revelando-os, também, como vítimas de uma sociedade patriarcal e androcêntrica.

\section{AS LACUNAS E AS AUSÊNCIAS}

A partir do exposto, é possível afirmar que os estudos feministas e/ou de gênero no Brasil continuam sendo feitos por mulheres, na sua maioria com pesquisas que versam especificamente sobre a condição feminina. Isso pode ser interpretado como herança do movimento feminista realizado por mulheres que defendiam os direitos dessa parcela da população mundial. A denúncia desse movimento era clara: os papéis coletivamente atribuídos ao gênero feminino eram tão conformados aos seus corpos que as impediam de ocupar os espaços sociais e as instituições de uma forma igualitária ou que pudessem explorar todo seu potencial biológico e mental (BEAUVOIR, 1970, p. 23). Dessa forma, os estudos ainda são vistos e entendidos por muitos e muitas docentes e estudantes como algo de interesse puramente feminino. Isso impede que muitos temas estudados na academia sejam analisados do ponto de vista do gênero que podiam estar entre as diversas categorias analíticas realizadas pelos estudantes. Os dados confirmam que, apesar de sua existência, os estudos feministas e a categoria de gênero ainda não são 
de conhecimento geral, e muitas vezes, essa categoria não é ensinada nas grades curriculares dos Programas.

Esse quadro possibilita, por exemplo, que em uma dissertação sobre o corpo como consumo na sociedade brasileira, e a relação com a religião, não apresente diferenciação sobre os corpos de homens e mulheres. Essa análise poderia alterar os resultados obtidos de forma profunda. O mesmo se pode dizer quando se faz uma pesquisa a respeito de determinadas religiões ou religiosidades, que não tendo o recorte de gênero, não consegue mensurar os impactos da religião sobre homens e mulheres que ocupam espaços diferenciados e hierarquizados nas religiões ou religiosidades.

Muitas pesquisas avaliadas, como descrito nos tópicos anteriores, trouxeram as mulheres como objeto de pesquisa. Entretanto essa "mulher" não existe numa sociedade não relacional, e não analisar os homens nessa trajetória faz que as conclusões acabem sendo incompletas e/ou incipientes. Dessa forma, encontram-se no campo da pesquisa muitos trabalhos acadêmicos sobre a violência contra a mulher e as perspectivas de saída dessa violência, mas temos poucas análises que revelem esses homens violentos, suas motivações, seus condicionamentos sociais e ideológicos, suas histórias pessoais que os levam a serem violentos com suas companheiras ou filhas. Como se deseja enfatizar a condição feminina nesse processo de dominação, tem-se uma ausência de análise crítica acerca das causas dos comportamentos masculinos; sobre as raízes de sua violência ou suposta superioridade de gênero; tampouco a respeito do processo de construção social responsável pelos seus costumes, hábitos e mentalidades acerca dos papéis de gênero e de seus comportamentos em relação à mulher. Por isso, não se encontraram entrevistas com agressores ou com opressores que pudessem cruzar os sentidos, formas de pensar e agir, bem como, mapear mudanças de crenças e comportamentos.

Dessa forma, fica evidente que, o uso correto da categoria de gênero propiciaria à sociedade perspectivas de mudanças na educação dos filhos e na regulagem dos relacionamentos, diminuindo assim, em longo prazo, a cultura de violência engendrada nas religiões e instituições religiosas. Segundo Francine Descarries (2000), os estudos feministas 
propiciam procedimentos sociológicos e metodológicos para constituir as mulheres enquanto categoria social e colocar o sexo/gênero como categorias de análise, bem como, para descontruir as representações e os mecanismos reconstitutivos da divisão social dos sexos e de outros sistemas de dominação. A proposta desses estudos é justamente promover a renovação dos saberes, estabelecer a certeza face à pretensa objetividade das ciências já instituídas, e buscar a transformação das práticas sociais e culturais de modo a formular uma visão diferente de sociedade, onde não se exclua ou se recuse "as experiências da metade ou mesmo da maioria do gênero humano", sob o vulto da categoria abstrata do humano universal (VARIKAS, 1993, p. 59).

De fato, é uma revolução analisar as mulheres nos estudos de religião, uma vez que, historicamente as instituições religiosas, especialmente as ocidentais, ${ }^{5}$ suas doutrinas, seus ritos e mitos, bem como, o arcabouço ético-moral, foram todos construídos historicamente pelos homens dentro de seus papéis sociais a eles designados; por seus corpos conformados biologicamente e socialmente; por suas categorias mentais conformadas pelo pensamento vigente. Então, as mulheres, historicamente falando, vinham como objetos de uso e consumo nas religiões dentro dos limites religiosos impostos para elas. Assim, encontramos os espaços de poderes e de comando permitidos aos homens, com sua forma específica de crer e agir, e as mulheres apresentando-se como meras consumidoras da religião, construídos por essa ação engendrada numa mentalidade androcêntrica e patriarcal.

Na medida em que o feminismo avançou nas sociedades ocidentais e as mulheres saíram da invisibilidade, elas foram mudando suas concepções sobre si mesmas e transformando suas ações e atitudes, o que foi refletindo nas religiões e nas práticas religiosas como questionamento e mudanças. Gerou-se, assim, um desconforto institucional

O budismo ofereceu um quadro diferente, ainda que complexo para essa questão. Isso porque se iniciou na Índia, no século VI a.C., como uma rebelião parcial contra o sistema religioso que acabou se transformando no hinduísmo. "O desagrado com a ênfase hindu na desigualdade era uma motivação-chave para a aceitação do budismo, e ainda que isso fosse particularmente dirigido contra o sistema de castas, tinha implicações nas relações de gênero também" (STEARNS, 2007, p. 63). 
diante das transformações que se processavam na sociedade que foi, aos poucos, incluindo as mulheres no mercado de trabalho, de consumo, das ciências etc.

Discussões se realizaram, inicialmente, na base das faculdades de teologia e depois se refletiram nos estudos da religião, sobre as possibilidades de as mulheres ocuparem espaços de equidade ou de poder nas instituições religiosas. Mulheres decidiram que poderiam ser pastoras dentro da religião cristã e isso fez que muitas denominações cristãs fossem ocupadas por mulheres que desejavam fazer faculdade de teologia para serem pastoras no mesmo ministério que seus pares masculinos. Outras desafiaram a sociedade, criando suas próprias instituições religiosas, mas reproduzindo as mesmas bases patriarcais na forma de construir os sistemas religiosos com as mesmas mentalidades androcêntricas vigentes na sociedade. Trocaram-se, muitas vezes, os agentes da liturgia onde as mulheres foram ocupando novos espaços, mas não se questionou o sistema religioso existente. E aquelas que ousaram questionar ou fazer diferente nessas instituições encontraram muitos obstáculos.

A produção feminista da religião não conseguiu se livrar da leitura machista que as interpretavam como seres inferiores aos homens, por conseguinte, nessa interpretação o conhecimento produzido pelas mulheres seria igualmente inferior. Essa postura impossibilitou que os homens assumissem o conhecimento produzido pelas mulheres publicamente, o que acabou reforçando a marginalização das mulheres. Visibiliza-se isso, por exemplo, quando se percebe muitas mulheres fazendo sua trajetória acadêmica, optando pela análise de gênero, mas não sendo convidadas ou selecionadas para trabalhar nos programas de Ciências da Religião ou de Teologia.

Outra coisa a levar em conta é que nem todas as mulheres trabaIham na perspectiva de gênero e tampouco escolhem como seu objeto de pesquisa o estudo das mulheres e de suas relações com os homens. Muitas mulheres preferem se distanciar dessa temática para "não se queimarem" junto às suas instituições, que as veriam como pessoas dissidentes ou rebeldes, e não lhes dariam espaço para posterior trabalho.

Dessa forma, se uma mulher deseja ser professora numa faculdade de teologia católica, mas vem estudar num Programa de Ciências da 
Religião, deve mostrar que concorda com o status quo da instituição e que é capaz de ser apenas reprodutora dos discursos milenarmente difundidos; deve mostrar que concorda plenamente com as decisões da instituição em todos os campos, inclusive na sua forma de pensar o feminino, seu corpo e sua atuação. Tudo que possa trazer confrontos, discordâncias e conflitos é altamente refutado pelas instituições religiosas na atualidade. Nos últimos vinte anos, com a ascensão de religiões centradas na mágica transcendental ou na prosperidade material como parâmetro para a vivência espiritual, a reprodução dos discursos tradicionais polarizou-se, afastando a possibilidade de mulheres e homens que repensassem o sistema religioso e de poder nas instituições religiosas.

Outra observação a ser feita é que existem várias pesquisas no campo das Ciências da Religião, que tem como objeto a biografia de uma mulher ou determinada condição de vida de um grupo social de mulheres. Entretanto, percebe-se que o(a) autor(a) não utiliza a categoria de gênero como uso metodológico para a análise de seu objeto, ou mesmo chega a contextualizá-la a partir de seu sexo, como se esse não fosse preponderante no seu contexto para determinar sua condição social e religiosa, suas ações com a espiritualidade, a escrita, as atitudes. É o caso de pesquisas sobre mulheres místicas ou experiência religiosa de grupo de mulheres, onde se estuda a vida da mística, explora sua orientação espiritual e traz sua contribuição para a vivência de uma espiritualidade que se tornou parte do sistema religioso.

Também se encontram pesquisadores(as) que percebem e descrevem as relações de desigualdade de gênero em suas pesquisas, mas não analisam essas mesmas relações. Apontam para a realidade de mulheres que têm que lutar contra a dominação masculina real e simbólica dentro da sua cultura e religião e, ao mesmo tempo, têm que lutar contra as imagens que a mídia cria e reforça delas mesmas. Descrevem a condição feminina no mundo religioso, trazem literatura sobre a sexualidade e seus usos, percebem as relações de gênero assimétricas, mas não fazem análise das relações de poder, e de gênero, tampouco constam nessas pesquisas referências bibliográficas de literatura de teologia feminista ou de gênero, apesar das pesquisas tocarem no assunto e permitirem aos seus autores uma análise da condição feminina na sociedade bra- 
sileira. Haveria alguma resistência institucional acadêmica à leitura e apontamentos dessa literatura nos Programas de Pós-Graduação em Ciências da Religião e Teologia? Seria apenas desconhecimento? Ou seria uma opção pessoal acadêmica dos autores(as)? Essas pesquisas e outras demonstram que, apesar da vasta produção teórica sobre a categoria de gênero, ela ainda é pouco utilizada nos Programas de Pós-Graduação em Ciências da Religião.

Também encontramos pesquisas onde se toca na condição feminina e sua maneira de ser, mas não se remetem os dados da pesquisa à crítica feminista. Aliás, essa tende a ser bem mais emblemática nas instituições religiosas, de forma que muitos autores(as) optam, muitas vezes, por pesquisas sobre a condição feminina que não envolva uma crítica feminista. É o caso de uma pesquisa que opta em falar do feminino sem questionar o próprio conceito de feminino e sem analisar as consequências dessa opção: "não tínhamos a intenção de defender uma visão feminista e sim reconhecer como as pessoas sentem e vivenciam o feminino" (JUNIOR, 2014, p. 258).

Outra lacuna que se percebe na trajetória desses programas é a ausência de uma crítica mais profunda em relação aos micropoderes, negligenciando as relações insidiosas que são construídas pelos membros religiosos na convivência cotidiana e preservadas pelo sistema religioso institucional, gerando aparentemente uma ideia de que basta mudar a ocupação do espaço de poder das igrejas e templos que a situação de gênero se tornaria igualitária. Ledo engano. Destinar os espaços de poder existentes e permitir que as mulheres os ocupem com a mesma disposição e perspectiva dos homens, apenas muda os sujeitos, muitas vezes fazendo que as mulheres se tornem sujeitos ocidentais religiosos masculinizados numa religião que continuará sendo patriarcal a despeito de sua posição na religião.

Esses fatos nos fazem refletir sobre a representação social dos conceitos de gênero e feminismo, e nos permitem constatar, na esteira de Eduardo Rabenhorst e Raquel Camargo (2013), que há um abismo entre os discursos construídos socialmente sobre o feminismo e as identificações mais pessoais com as injustiças sofridas pelas mulheres. Como salientam os autores "em outras palavras, é comum que as re- 
presentações sociais em torno do feminismo reflitam um julgamento $a$ priori negativo, enquanto algumas reivindicações desse movimento são percebidas como justas, apesar de estarem inseridas nesse contexto de negatividade" (RABENHORST e CAMARGO, 2013, p. 987). A grande questão é que muitos homens e mulheres temem aderir a valores dos quais muitos(as) não gostariam de abrir mão, como feminilidade e um projeto de vida pautado pelo desejo de casamento e de maternidade. Também há a existência de certa resistência à aceitação de novos modelos de família, que incluem a união/casamento de pessoas homossexuais, famílias mononucleares, entre outros arranjos. Essa resistência, com certeza, está associada às tensões decorrentes de alguns modelos religiosos patriarcais e conservadores, e que denota a dificuldade já mencionada de se livrar do habitus masculino, de que fala Pierre Bourdieu (2009).

\section{CONSIDERAÇÕES FINAIS: AS CONTRIBUIÇÕES E OS DESAFIOS PARA A PESQUISA}

As pesquisas envolvendo o gênero, seus papéis designados, sua construção social, suas relações nas instituições religiosas, trouxeram o mérito de colocar em evidência a mulher. Essa conquista de visibilidade aos corpos e vozes de mulheres, que até então estavam no anonimato, foi um grande salto nas pesquisas religiosas. Saiu-se do modelo sociológico de estudo das religiões enquanto instituição que influenciava ou determinava as práticas religiosas, para revelar os sujeitos individuais e coletivos que realmente edificam a religião e mantêm a instituição.

Em síntese, as mulheres que afloraram das pesquisas acadêmicas de gênero revelam que elas vêm adentrando áreas antes confinadas apenas aos homens no espaço religioso. Timidamente, se tenta construir novos tratados religiosos que possam inferir concretamente na desconstrução de velhos sistemas e na construção de novos sistemas religiosos onde o corpo feminino, suas experiências religiosas, sua visão de mundo e do transcendente possam coexistir com as novas experiências masculinas. Entretanto, alguns desafios permanecem, pois o espaço acadêmico ainda é muito androcêntrico, e persiste numa lógica masculina patriarcal, onde as relações valorizadas são aquelas 
erguidas sob um sistema quiriárquico e de cultura autoritária. Os estudos dos clássicos, as teorias acadêmicas, a metodologia científica e as plausibilidades aceitáveis ainda são aqueles construídos a partir de um paradigma masculino de pensar que se cristalizou, de tal forma, que pouco se consegue mudanças nessa perspectiva. Desse modo, mesmo as mulheres que entenderam a categoria de gênero e a utilizam em seus trabalhos, são obrigadas a manter essa lógica, seja nas suas instituições religiosas, seja no ambiente acadêmico. Como ser plenamente mulher numa sociedade masculina onde para ser vista tem que se tornar um sujeito masculinizado?

Houve um esforço notável nos Programas de Pós-Graduação em Ciências da Religião em trazer disciplinas e reflexões que favorecessem o reconhecimento da mulher e a teoria de gênero, mas esse empenho ainda foi muito pequeno diante da necessidade. Há que se continuar com a despatriarcalização da cultura brasileira, que possa reconhecer como legítimo o agir das mulheres nas esferas de poder religioso e universitário.

Quando se pensou que a questão de gênero na sociedade e na universidade brasileira já estava concretizada, apareceram discursos difundidos por agentes políticos e lideranças religiosas, pontuando que gênero seria apenas uma ideia como outra e se difundiu a "ideologia de gênero" como algo maléfico e prejudicial às relações familiares, sociais e políticas. Questionou-se a educação de gênero que estava em curso nas escolas e universidades brasileiras e a mídia nacional com as redes sociais propagaram essas ideias. Numa relação dialética, percebe-se uma luta entre o que foi e o que será entre conservar e transformar. Denunciar as desigualdades de gênero é provocar novas relações de gênero e de poder questionando o sistema capitalista, a organização social vigente, as políticas de governabilidade mantenedoras do patriarcado e os sistemas religiosos que trazem representações sociais e mentais. Não é fácil entender que crenças têm que ser desmontadas para que novas crenças sejam criadas e essa é uma das tarefas que o uso da categoria de gênero pode propiciar ao estudante de Ciências da Religião, quando este consegue aplicá-la em suas pesquisas, qualquer que seja seu objeto de estudo. 
Enquanto os estudos de gênero continuarem sendo apenas um departamento da universidade, uma disciplina para interessados ou mesmo algo de um grupo de mulheres do Programa de Pós-Graduação, eles não cumprirão a sua função de questionar a desigualdade e o poder entre os gêneros assim constituídos.

É necessário que os Programas de Estudos em Ciências da Religião continuem a incentivar as produções de pesquisa sobre os estudos feministas e de gênero, que possam contratar mais docentes versados e interessados no desenvolvimento dessa temática, que possam trazer como disciplina essa metodologia de estudo nas religiões para que se aumentem significativamente os resultados obtidos dessas pesquisas na socialização com a sociedade.

\section{REFERÊNCIAS}

BEAUVOIR, Simone. O segundo sexo. Rio de Janeiro: Nova Fronteira, 1980.

BOURDIEU, Pierre. A dominação masculina. Rio de Janeiro: Bertrand Brasil, 2009.

BUTLER, Judith. Gender Trouble: feminism and the subversion of identity. New York: Routledge, 1997.

DERRIDA, Jacques. Gramatologia. São Paulo: Perspectiva, 1973.

DESCARRIES, Francine. Teorias feministas: liberação e solidariedade no plural. Revista Textos de História. Feminismos: teoria e perspectivas. Brasília: UnB, 2000, vol. 8, n. $1 / 2$, p. 09-46.

DISSERTAÇÕES. Disponível em: http://bdtd.biblioteca.ufpb.br/simple-search?query=cie ncias+da+religi\%C3\%A30. Acesso em: 18 out. 2017.

DISSERTAÇÕES. Disponível em: http://up.mackenzie.br/stricto-sensu/ciencias-da-religiao/ teses-e-dissertacoes/. Acesso em 25 out. 2017.

DISSERTAÇÕES. Disponível em: http://www.sistemas.pucminas.br/BDP/SilverStream/ Pages/pg_BDPPrincipal.html. Acesso em 2 dez. 2017.

DISSERTAÇÕES. Disponível em: http://www.ufff.br/ppcir/curso/defendidas/dissertacoes/. Acesso em: 12 nov. 2017.

DISSERTAÇÕES. Disponível em: https://paginas.uepa.br/ppgreligiao/index. php?option=com_rokdownloads\&view=folder\&ltemid=23. Acesso em 2 dez. 2017.

DISSERTAÇÕES. Disponível em: https://www.puc-campinas.edu.br/pos-graduacao/programa-de-pos-graduacao-em-ciencias-da-religiao-mestrado-2/\#teses. Acesso em 3 dez. 2017. 
DISSERTAÇÕES. Disponível em: https://www.sigaa.ufs.br/sigaa/public/programa/defesas. jsf?lc=pt_BR\&id=857. Acesso em: 25 out. 2017.

DISSERTAÇÕES E TESES. Disponível em: http://tede2.pucgoias.edu.br:8080/simplesear ch?query=ciencias+da+religi\%C3\%A30. Acesso em 3 dez. 2017.

DISSERTAÇÕES E TESES DO PROGRAMA DE PÓS-GRADUAÇÃO DA PONTIFÍCIA UNIVERSIDADE CATÓLICA DE SÃO PAULO. Disponível em: http://www.pucsp.br/pos-graduacao/ mestrado-e-doutorado/ciencia-da-religiao. Acesso em: 20 nov. 2017.

DOCENTES DOS PROGRAMAS DE PÓS-GRADUAÇÃO EM CIÊNCIAS DA RELIGIÃO E TEOLOGIA DO BRASIL. Disponível em: http://www.anptecre.org.br/index. php?pagina=formulario\&tela=28. Acesso em 4 dez. 2017.

FOUCAULT, Michel. As palavras e as coisas. São Paulo: Martins Fontes, 1985.

FRIEDAN, Betty. Mística feminina. Petrópolis: Vozes, 1971.

INFORMAÇÕES DO MESTRADO EM CIÊNCIAS DA RELIGIÃO. Disponível em: http://www. faculdadeunida.com.br/site/cursos/mestrado/informacoes-gerais. Acesso em: 25 out. 2017. INFORMAÇÕES DO PPGCR. Disponível em: http://www.ufjf.br/ppcir/. Acesso em: 12 nov. 2017.

JUNIOR, Reinaldo S. A mãe sagrada unindo tradições: uma análise fenomenológica do sincretismo religioso brasileiro. Tese (Doutorado em Ciências da Religião). Universidade Federal de Juiz de Fora. Juiz de Fora, 2014.

MARQUES, Ângela C. Borges; ROCHA, Marcelo. Memórias da fase inicial da Ciência da Religião no Brasil - Entrevistas com Edênio Valle, José J. Queiroz e Antonio Gouvêa Mendonça. REVER-Revista de Estudos da Religião, São Paulo, março, p. 192-214, 2007. MENDONÇA, A. G. O fim de um tempo: Última aula na Pós-Graduação em Ciências da religião (15 de agosto de 2002). Estudos de religião, São Paulo, ano XXII, n. 34, p. 234248, jan./jun. 2008.

MURARO, Rose M. Os seis meses em que fui homem, 2. ed. Rio de Janeiro: Rosa dos Tempos, 1991.

RABENHORST, Eduardo Ramalho; CAMARGO, Raquel Peixoto do Amaral. (Re)presentar: contribuições das teorias feministas à noção da representação. Revista Estudos Feministas. Florianópolis, v. 21, n. 3, p. 981-1.000, dez. 2013.

RIBEIRO, Margarida F. S. Trajetória das mulheres na Bíblia e no Metodismo: rastros, memória e desafios. Educação \& Linguagem, v. 17, n. 1, p. 117-132, jan./jun. 2014.

SCOTT, Joan W. Gênero: uma categoria útil de análise histórica. Educação \& Realidade. Porto Alegre, vol. 20, n. 2, jul./dez. 1995.

SPIVAK, Gayatri Chakravorty. Pode o subalterno falar? Belo Horizonte: Editora da UFMG, 2010. 
STEARNS, Peter N. História das relações de gênero. São Paulo: Contexto, 2007.

TESES. Disponível em: http://www.ufff.br/ppcir/curso/defendidas/teses/. Acesso em: 12 nov. 2017.

TESES E DISSERTAÇÕES. Disponível em: http://portal.metodista.br/posreligiao/publicacoes/teses-e-dissertacoes/teses-e-dissertacoes. Acesso em: 25 nov. 2017.

VARIKAS, Eleni. "Féminisme, modernité, postmodernisme: pour un dialogue des deux còtés de 1'océan.” In: BERGER, Denise. Féminismes auprésent. Paris: L'Harmattan, 1993.

Submetido em: 12-5-2018

Aceito em: 14-6-2018 